\title{
Em busca do fortalecimento da soberania: uma análise do Tratado de Cooperação Amazônia - TCA
}

\author{
In pursuit of strengthening the sovereignty: an analysis of the Amazon \\ Cooperation Treaty - TCA
}

Nery Jocasta Denis Asconavieta ${ }^{1}$

\section{Resumo}

A década de 1970 é considerada uma época de crises, mas que pode ser considerada ressonância de crises profundas gestadas desde os anos de 1960. Pode-se citar a crise de maio em 1968 da França; a Guerra do Vietnã; a crise do Petróleo; a Guerra Fria entre duas superpotências, a saber, a ex-União das Repúblicas Socialistas Soviéticas e os Estados Unidos da América; os conflitos regionais do Oriente Médio que apresentaram um aumento considerável; a onda revolucionária da década de 1970 em diversas partes do mundo; a doutrina de segurança nacional do governo Nixon, aplicado nos países ditatoriais da América Latina e a consequente modificação em fins dos anos de 1970 para uma lenta abertura política influenciada pelo governo Carter. Neste cenário turbulento, no ano de 1978 foi assinado em Brasília, o Tratado de Cooperação Amazônica (TCA). Os países partícipes deste foram Bolívia, Brasil, Colômbia, Equador, Guiana, Peru, Suriname e Venezuela. Dentre os objetivos deste estão a promoção e o desenvolvimento da região amazônica, que para ocorrer, dependeria da integração dos países partícipes, bem como a utilização consciente dos recursos naturais e consequentemente preservação deste, o que garantiria a defesa da soberania sobre seus respectivos territórios. O presente artigo visa analisar, compreender e explanar acerca do conceito de soberania; para tal fim, tem como objeto a análise do Tratado de Cooperação Amazônica (TCA).

Palavras-Chave: Amazônia; Integração Regional; Soberania.

\begin{abstract}
The 1970 is considered a time of crisis, but that can be considered resonances gestated deep crisis since the 1960s can cite the crisis of May 1968 in France.; the Vietnam War; The oil crisis; the Cold War between two superpowers, namely the former Union of Soviet Socialist Republics and the United States of America; regional conflicts in the Middle East that showed a significant increase; the revolutionary wave of 1970 in many parts of the world; the national security doctrine of the Nixon administration, applied in dictatorial countries of Latin America and the consequent change in the late 1970s to a slow political openness influenced by the Carter administration. In this turbulent scenario, the year 1978 was signed in Brasilia, the Amazon Cooperation Treaty (ACT). The participants in this countries were Bolivia, Brazil, Colombia, Ecuador, Guyana, Peru, Suriname and Venezuela. Among the objectives of this are the promotion and
\end{abstract}

\footnotetext{
${ }^{1}$ Graduada em Licenciatura e Bacharelado em História pela Universidade Federal de Roraima
} 
development of the Amazon region, that to occur, depend on the integration of the participants countries, as well as the conscious use of natural resources and preservation of this result, which would ensure the defense of sovereignty over their respective territories. This article aims to analyze, understand and explain about the concept of sovereignty; for this purpose, has the purpose of analyzing the Amazon Cooperation Treaty (ACT).

Keywords: Amazon; Regional Integration; Sovereignty, ACT.

Artigo recebido em: 01/02/2014

Artigo aprovado para publicação em: 25/02/2014

\section{Introdução}

O estudo das relações entre os países amazônicos tem aumentado nos últimos anos. Salienta-se que são 8 países soberanos e uma possessão francesa que compartilham esse espaço e o tornam diversificado em termos culturais, étnicos, políticos, econômicos e sociais. Diversidade que se encontra envolta pela bacia e/ou floresta amazônica.

Foi dessa diversidade que surgiram os primeiros questionamentos, dando origem à pesquisa aqui apresentada. Na busca de respostas acerca da relação/integração entre países tão diferentes, apesar de possuírem aspectos comuns, como terem sido colonizados em um mesmo tempo e possuírem sociedades plurais.

O presente artigo tem como objetivo compreender o conceito de soberania através da análise do Tratado de Cooperação Amazônica - TCA. Vale salientar que a pesquisa não teve o intuito de trabalhar com todos os conceitos presentes no referido tratado, mas enfatizar um dos aspectos centrais para a compreensão da década de 1970, especificamente na região amazônica. Outros conceitos foram identificados no TCA, mas em decorrência do tempo de conclusão da pesquisa, não puderam ser estudados, mas poderão servir de aporte para pesquisas futuras e serão apresentados posteriormente.

A priori, na fase ainda da pesquisa, julgamos que nosso aporte teórico estaria balizado na Historia das Relações internacionais, campo bastante fecundo nas academias brasileiras. Trata-se, como explica Duroselle (2000) do estudo das Relações Internacionais tendo como aporte a História. Este, como cita Marinho (2008) é a forma

Revista Eletrônica da ANPHLAC, ISSN 1679-1061, n. 16, p. 115 -134, Jan./Jul. 2014. http://revista.anphlac.org.br 
mais tradicional do estudo das Relações Internacionais, ou seja, no estudo da Política Internacional (interna e externa) e da Vida Internacional que se trata das relações privadas. Estas premissas juntas formam as Relações Internacionais, a primeira enfatiza o papel estatal; já a segunda o caráter privado e, por vezes, individual na tomada de decisões de caráter internacional.

Importante ressaltar que para a análise do conceito de soberania presente no TCA nos reportamos à Koselleck (1992), que defende que todo conceito é concomitantemente Fato e Indicador, ou seja, não é somente um fenômeno linguístico, mas também um indicativo de algo que se situa para além da língua. Assim é possível inferir que todo conceito ultrapassa as barreiras linguísticas e que a partir deste, se pode pensar a realidade histórica e atuar de forma concreta sobre esta.

A principal fonte deste trabalho foi o Tratado de Cooperação Amazônica, este é o ponto de partida, a partir deste documento, realizaram-se o exame, identificação e posterior análise e compreensão do conceito de soberania explícito e implícito no TCA.

\section{0: Uma Década de Crises}

Para a efetiva compreensão da década de 1970 se faz necessário salientar alguns pressupostos que tiveram maior influência na América Latina, a começar pela Guerra Fria (1945-1990), ou seja, do lançamento das bombas atômicas no Japão pelos Estados Unidos, até o fim da União Soviética. Este período de tempo é caracterizado pelo constante confronto entre Estados Unidos e Ex-União Soviética, duas potências que se firmaram economicamente após o término da Segunda Guerra Mundial (HOBSBAWM, 1995).

Segundo Hobsbawm (1995), este período pode ser divido em duas partes, tendo como divisor de águas, o início da década de 1970. Após a Segunda Guerra Mundial, a situação tornou-se bastante estável e assim permaneceu até a década de 1970, quando o sistema internacional e as unidades que faziam parte deste, entraram em crise tanto econômica, quanto política. Daí em diante pode-se dizer que teve inicio uma Segunda Guerra Fria caracterizada por uma grande corrida por aparato bélico, grande

Revista Eletrônica da ANPHLAC, ISSN 1679-1061, n. 16, p. 115 -134, Jan./Jul. 2014. http://revista.anphlac.org.br 
febre militar, retórica apocalíptica constante e uma participação ativa dos Estados Unidos em conflitos regionais como no Oriente Médio e na América Latina.

\section{A Doutrina de Segurança Nacional}

Não há como falar do período da Guerra Fria, sem explanar acerca da chamada Doutrina Nixon e da Doutrina de Segurança Nacional implantada no Brasil, pois estas possibilitam a contextualização e consequente compreensão da década de 1970. Nixon (1969-1974) foi o grande difusor da chamada Doutrina Nixon. Este presidente, porém, é considerado um dos piores do país pelo escândalo de Watergate, resultante de uma invasão aos escritórios do Comitê Nacional Democrata. Sua doutrina resultado de sua grande habilidade em relação à política externa do país, juntamente com Kissinger, seu secretário de Estado, pôs fim à intervenção direta dos EUA, principalmente no Oriente Médio, ao invés disto, houve a participação indireta nos conflitos da região, em que os grupos de esquerda foram financiados, treinados e armados pelo Pentágono.

Segundo Kupchan, “A Doutrina Nixon, em contrapartida, era uma indicação de que as tropas norte-americanas gastariam menos tempo no Terceiro Mundo do que na década de 60" (1987, p. 33). Já na América Latina, ao contrário, houve o envolvimento do governo americano na derrubada do presidente chileno Salvador Allende e no banho de sangue que se seguiu com Pinochet. Pode-se dizer, de modo geral, segundo Francisco Carlos Teixeira Silva (2007), que o governo Nixon foi fomentador de golpes militares em toda a América Latina e no fortalecimento destas, no caso do Brasil. Neste último, na difusão da Doutrina de Segurança Nacional.

A Doutrina de Segurança Nacional, implementada e divulgada pela Escola Superior de Guerra (ESG), fundada em 1949, após a Segunda Guerra Mundial que:

(...). Terminada a guerra, toda essa geração de oficiais, em fluxo maciço, passou a freqüentar cursos militares americanos (...). Quando começam a retornar ao Brasil já então profundamente influenciados por uma nova concepção à respeito de como entender a Defesa Nacional. Nas escolas americanas tinham aprendido que não se tratava mais de fortalecer o Poder Nacional contra eventuais ataques externos, e sim contra um inimigo interno que procurava solapar as instituições. Voltam não só convencidos das novas propostas sustentadas pelos estrategistas norte-americanos, mas também interessados em repetir

Revista Eletrônica da ANPHLAC, ISSN 1679-1061, n. 16, p. 115 -134, Jan./Jul. 2014. http://revista.anphlac.org.br 
aqui alguma experiência semelhante as do National War College criado naquele país, em 1946, com o objetivo de congregar civis e militares no estudo de problemas referentes à estratégia de Defesa e Poder Nacional. (Arquidiocese de São Paulo, 1985, p. 70).

Esta doutrina, resultante da mudança no conceito de segurança nacional, tradicionalmente concebido como defesa das fronteiras nacionais contra forças externas, que a partir dos anos de 1950 e com o Ato Institucional n.5 de 1968 passa a lutar contra os chamados "inimigos internos", subversivos ao regime ditatorial implantado no país em 1964 (Arquidiocese de São Paulo, 1985).

Dessa forma, o Estado implantou um aparato repressivo gigantesco e autônomo tornando certa a afirmação de que na década de 1970, há existência de um verdadeiro Estado dentro do Estado (Arquidiocese de São Paulo, 1985), pois é indispensável à defesa nacional, bem como um planejamento da segurança do país, como exemplo desse aparato está a criação do:

Sistema Nacional de Informações (SNI) que poderia ser visualizado como uma pirâmide que tinha como base as câmaras de torturas e interrogatórios e, no vértice, o Conselho de Segurança Nacional (CSN) (Arquidiocese de São Paulo, 1985, p.11).

Todo esse aparato repressivo teve como resultado a estabilidade do regime militar brasileiro que, no início na década de 1970, conseguiu vencer diversos grupos de subversão como, por exemplo, a Guerrilha do Araguaia ${ }^{2}$.

Essa estabilidade nos regimes militares foi abalada por condicionantes externos no final da década de 1970, como a Crise e recessão da economia mundial. Esta crise é ocasionada em parte tanto pela Guerra do Yom Kippur ${ }^{3}$, em 1973 e a Guerra IrãIraque 1980 e $1988^{4}$; que trouxeram consigo o Bloqueio Petrolífero e a consequente crise mundial dos juros externos de 1982.

\footnotetext{
${ }^{2}$ A Guerrilha do Araguaia foi um movimento guerrilheiro existente na região amazônica brasileira, ao longo do rio Araguaia, entre fins da década de 1960 e a primeira metade da década de 1970. Tinha por objetivo fomentar uma revolução socialista, a ser iniciada no campo, baseada nas experiências vitoriosas da Revolução Cubana e da Revolução Chinesa.

${ }^{3}$ A Guerra do Yom Kippur foi um conflito militar ocorrido de 6 de Outubro a 26 de Outubro de 1973, uma coalizão de estados árabes liderados por Egito e Síria contra Israel.

${ }^{4}$ A Guerra Irã-Iraque foi um conflito militar entre o Irã e o Iraque entre 1980 e 1988. Foi o resultado de disputas políticas e territoriais entre ambos os países.

Revista Eletrônica da ANPHLAC, ISSN 1679-1061, n. 16, p. 115 -134, Jan./Jul. 2014. http://revista.anphlac.org.br
} 
Embora o choque dos preços do Petróleo tenha sido importante, na década de 1970, a abundância de capitais existentes no mercado internacional permitiu ao Brasil certa navegação sem grandes turbulências, entre 1973 e 1974, ou seja, da passagem do governo Médici para o governo Geisel. O que leva a crer, por exemplo, que a crise petrolífera não desempenha um papel fundamental nas origens da crise política no Brasil (SILVA, 2007). Para este, a recessão de 1982 atingiu mais o país que a crise do petróleo, por isso pode-se afirmar que o Brasil no governo Geisel conseguiu fazer frente à crise.

Francisco Carlos Teixeira Silva (2007) defende que a crise econômica não leva à abertura política e sim que o cenário econômico otimista tendeu a facilitar a transição, ou seja, a crise econômica condicionou o ritmo da redemocratização no país, levando a opinião pública voltar-se contra o regime. A grande tese do autor é a de que a abertura democrática ocorrida na maioria dos países da América Latina decorreu da mudança da postura dos EUA em relação à sua política externa no governo de Jimmy Carter (1977-1981). Carter, ao contrário dos seus antecessores republicanos, influenciou o processo de abertura democrática de países da América Latina, quase todos governados, naquele então, por ditaduras militares.

Em 1977, as discussões entre Carter com o então presidente brasileiro Ernesto Geisel influenciou o processo de abertura política no país, que seria continuado por João Figueiredo. O que estava em pauta com tal postura assumida por Carter era a recuperação do prestígio mundial americano, ou seja, a sua credibilidade mundial. $\mathrm{O}$ objetivo principal com tal posição era o estabelecimento de regimes democráticos estáveis. Válido salientar que a retórica americana acerca dos direitos humanos jamais colocou seriamente em risco, por exemplo, a ditadura de Pinochet. Por isso que Silva (2007), alerta que, no caso brasileiro, as críticas ao governo Geisel, encobriam uma nítida oposição à aproximação do Brasil com a Alemanha Ocidental e o consequente Acordo Nuclear assinado entre os dois países em 12 de junho de 1975 em que a Alemanha se comprometeu a exportar toda a tecnologia necessária para a obtenção do ciclo completo de enriquecimento de material físsil ao Brasil; bem como ao extremo intervencionismo praticado pelo Brasil, inclusive com o estabelecimento de reserva de mercado em áreas de interesse americano.

Revista Eletrônica da ANPHLAC, ISSN 1679-1061, n. 16, p. 115 -134, Jan./Jul. 2014. http://revista.anphlac.org.br 
Essa nova postura brasileira na política externa do governo Geisel é resultado do chamado "pragmatismo responsável", pois enquanto o governo de Médici passou por um período eufórico do "milagre brasileiro", a crise do petróleo em 1973, aliada a problemas estruturais no modelo de desenvolvimento econômico brasileiro, deixaram duras problemáticas a serem resolvidas por Geisel o que o forçou a mudanças de sua orientação nas relações externas, reflexo das dificuldades internas do país (LOHBAUER, 2000).

\title{
O Pragmatismo Responsável do governo Geisel: uma nova política externa, um novo olhar para a região Amazônica
}

Ernesto Geisel e seu Chanceler Antonio Francisco Azeredo da Silveira, que permaneceu na chefia do Ministério das Relações exteriores durante todo o governo (1974-1978) estavam a par dos novos desafios da política externa, pois como explica Ligiero (2011), esta nova forma de lidar com as questões relativas à política externa, estava ligada a uma tentativa de inserção internacional do Brasil.

Na primeira reunião ministerial de seu governo, ocorrida em 19 de março de 1974, Ernesto Geisel enfatiza as seguintes questões em relação à política externa:

\begin{abstract}
No campo da política externa, obedecendo a um pragmatismo responsável e consciente dos deveres da Nação, bem mais adulta, no terreno da solidariedade e cooperação internacionais em prol do progresso da humanidade e da paz mundial, daremos relevo especial ao nosso relacionamento com as nações-irmãs da circunvizinhança de aquém e além-mar. Impulsionaremos a ação diplomática, alerta sempre para a detecção de novas oportunidades e a serviço, em particular, dos interesses de nosso comércio exterior, da garantia do suprimento adequado de matérias-primas e produtos essenciais e do acesso à tecnologia mais atualizada de que não dispomos ainda, fazendo para tanto, com prudência e tato mas com firmeza, as opções e os realinhamentos indispensáveis (Discurso de Ernesto Geisel, 19 de março de 1974).
\end{abstract}

Assim sendo, esta política externa estava balizada em três conceitos: pragmatismo (pois se lutava contra ideias preconcebidas e ideais retóricos), responsabilidade (seguia parâmetros éticos, moderados, tendendo ao desenvolvimento

Revista Eletrônica da ANPHLAC, ISSN 1679-1061, n. 16, p. 115 -134, Jan./Jul. 2014. http://revista.anphlac.org.br 
econômico e social) e ecumenismo (rejeitava a ideia de hegemonia e há uma valorização de uma convivência pacifica com outros países) (LIGIERO, 2011).

Entre as opções do chamado "pragmatismo responsável" pode-se citar: a intensificação do multilateralismo, a mudança da posição brasileira em relação à questão do Oriente Médio, que mudaria de uma neutralidade pró-Israel para um apoio à posição árabe; não apoio ao colonialismo português e o reconhecimento da Angola; o estabelecimento de relações com a China Comunista; ampliação das relações econômicas com os países europeus, principalmente a Alemanha; e o desenvolvimento das relações com os chamados países da América Latina. Em todas estas opções verifica-se uma crescente tensão com os Estados Unidos.

Segundo Leite (2011), a política externa brasileira no continente americano estava dividida nos seguintes setores: região platina; região amazônica e Chile; América Central, México e Caribe; e foros multilaterais latino-americanos. No entanto, nossos objetivos, se desdobrarão sobre a região amazônica, para melhor compreensão dos conceitos geopolíticos da década de 1970 incorporados na analise do Tratado de Cooperação Amazônica - TCA, mas para tal fim, se fez necessário uma prévia análise da política externa aplicada à região.

O governo de Ernesto Geisel interessou-se de uma forma bastante peculiar com a região amazônica, pode-se dizer que este elevou a um novo patamar a região na agenda internacional brasileira. De acordo com Leite (2011) e Moreira (2012), uma forma de demonstrar esse interesse é o incentivo à criação do Tratado de Cooperação Amazônica - TCA, pois dessa forma, o Brasil promove o multilateralismo, bem como o fortalecimento com os países vizinhos. Anteriores ao Tratado de Cooperação Amazônica, as tentativas de integração entre os países amazônicos tinham resultado em medidas domesticas e bilaterais.

No dia 3 de julho de 1978 foi assinado em Brasília, o Tratado de Cooperação Amazônica - TCA. Os países partícipes deste foram Bolívia, Brasil, Colômbia, Equador, Guiana, Peru, Suriname e Venezuela.

Os principais objetivos deste tratado estão explícitos no Primeiro Artigo que diz:

Revista Eletrônica da ANPHLAC, ISSN 1679-1061, n. 16, p. 115 -134, Jan./Jul. 2014. http://revista.anphlac.org.br 
As Partes Contratantes convêm em realizar esforços e ações conjuntas a fim de promover o desenvolvimento harmônico de seus respectivos territórios amazônicos, de modo a que essas ações conjuntas produzam resultados equitativos e mutuamente proveitosos, assim como para a preservação do meio ambiente e a conservação e utilização racional dos recursos naturais desses territórios (TCA, 1978).

Dessa forma, está explicito no Tratado que a promoção do desenvolvimento da região amazônica depende da integração dos países partícipes, bem como a utilização consciente dos recursos naturais ${ }^{5}$ e consequentemente a preservação deste, ou seja, criar mecanismos de desenvolvimento da região, sem afetar o meio ambiente, sem que nenhum dos países membros abrisse mão de sua soberania, ao contrário, a integração permitiria a conservação e fortalecimento desta (CALDERÓN, 2007; MOREIRA, 2012).

A temática relativa à manutenção e fortalecimento da soberania foi amplamente contemplada no tratado, uma vez que a manutenção e a proteção das fronteiras na Amazônia constituíam-se em questões centrais para Geisel.

\section{Soberania: defesa da Amazônia}

Geralmente quando se reflete acerca do conceito de soberania há os seguintes questionamentos: Qual a sua função? Quais suas restrições e abrangências? Qual sua importância no entendimento do poder político? Dessa forma, são válidas as proposições de Norberto Bobbio, Nicola Matteucci e Gianfranco Pasquino no Dicionário de política (1998), em que definem a soberania da seguinte forma:

Em sentido lato, o conceito político-jurídico de soberania indica o poder de mando de última instância numa sociedade política e, consequentemente, a diferença entre esta e as demais associações humanas em cuja organização não se encontrava esse poder supremo, exclusivo e não derivado. Este conceito está, pois, intimamente ligado ao de poder político: de fato, a soberania pretende ser a racionalização jurídica do poder, no sentido de transformação da força em poder legítimo, do poder de fato em poder de direito (BOBBIO; MATTEUCCI; PASQUINO, 1998, p. 1179).

\footnotetext{
${ }^{5}$ Importante enfatizar que o presente trabalho não pretende discutir acerca da questão ambiental e integração, temáticas tão em voga na década de 1970.

Revista Eletrônica da ANPHLAC, ISSN 1679-1061, n. 16, p. 115 -134, Jan./Jul. 2014. http://revista.anphlac.org.br
} 
Esta definição enfatiza dois referenciais básicos sobre a soberania: sua caracterização como mando de última instância; e a origem de suas atribuições tanto no poder quanto no direito (HERMANN, 2011).

O primeiro a apresentar o conceito de soberania foi Jean Bodin, que o define como sendo um poder absoluto e perpétuo. Este defende um Estado forte e centralizador com vistas a unificar o Estado e estabilizá-lo, por esta razão, qualquer noção de soberania partilhada ou limitada lhe parece absurda e até perigoso, tanto que este defendia que mesmo que haja tirania não pode haver restrições ou limitações ao exercício da soberania. Segundo Hermann (2011, p.65) "Bodin temia mais a anarquia do que desgostava da tirania", pois a soberania para o autor é o eixo sobre a qual se move o Estado.

Outro importante teórico acerca da soberania é Thomas Hobbes. Este diferentemente de Bodin em que o governante encontra-se limitado pelo direito natural e defende que o Estado é ilimitado e onipotente (HERMANN, 2011). Hobbes pesquisa os males que pode advir da soberania dos soberanos. Segundo o autor, o homem tem que menosprezar o seu instinto egoísta em prol de uma civilidade, daí decorre o contrato social. Segundo (GUERRA, 2004) o Leviatã representa bem essa ideia. Vários homenzinhos, na mão direita uma espada como representação de força do Estado, na mão esquerda um pastoral representando a proteção da cidade. O que coloca o Leviatã como a representação nata da soberania ou do poder soberano.

Tanto para Hobbes, como Rousseau e Marshall a soberania é una, indivisível, inalienável e imprescritível. Não comporta gradações e não soluciona problemas do Estado moderno. Em O Contrato Social Rousseau defende que a soberania é do povo que o transfere ao Estado. Tal como Hobbes, este é um contratualista, ou seja, acredita que o homem se institui a partir de um contrato social, no qual o homem em troca de proteção do Estado abre mão de sua liberdade e de ser um homem natural (MORE, 2007; RIBEIRO, 2006).

Do ponto de vista jurídico, Hans Kelsen, que inspirou as concepções de paz internacional e da Liga das Nações após a Primeira Guerra Mundial, pois não em sua Revista Eletrônica da ANPHLAC, ISSN 1679-1061, n. 16, p. 115 -134, Jan./Jul. 2014. http://revista.anphlac.org.br 
concepção não há fronteiras entre o ordenamento jurídico interno e o internacional, diz que a soberania não é um conceito jurídico e por isso não pode ser analisada por estes termos. Para ele, a soberania é o fundamento do Estado, pois é esse traço que o caracteriza como tal, tanto interna ou externamente (HERMANN, 2011; ROCHA, 2009).

Outro autor bastante interessante no que tange às suas concepções de soberania é Hermann Heller. Diferentemente de Kelsen que propõe um direito internacional desvinculado das particularidades estatais, Heller coloca os Estados soberanos como unidades fundamentais e constituintes do direito internacional. São os Estados soberanos anteriores ao direito internacional e não o contrário (HELLER, 1995; HERMANN, 2011).

Com um olhar liberal surge o pensamento de Georges Burdeau no século XX, que percebe a soberania como um poder social a serviço e bem-estar da população. $O$ autor corrobora com a conhecida soberania do povo de Rousseau, já explicitada. Burdeau é considerado o primeiro teórico que pensa em um Estado Liberal e que concebe a legitimação constitucional do poder dos governantes (ROCHA, 2009).

Dessa forma, verifica-se que segundo Edson Luiz Tortola (apud, DIAS; SOUZA, 2011):

\begin{abstract}
A soberania foi sendo reconstruída ao longo do tempo, na medida em que o fenômeno da globalização e mundialização do capital impuseram ao Estado a adoção da integração de normas jurídicas, oriundas de ordenamento jurídico internacional, rompendo, por conseguinte, o conceito de Rousseau de soberania una, inalienável e indivisível.
\end{abstract}

Assim, no século XX o conceito de soberania relativa ganha força, principalmente depois da Primeira e Segunda Guerra Mundial, pondo em xeque a ilimitada liberdade de ação dos Estados.

Percebe-se, então, que o conceito de soberania, às vezes tido como de fácil compreensão e conceituação, não é tão simples quanto aparenta. Pois este não é estático, como já demonstrado, mudando de acordo com o contexto histórico envolvido. Para a pesquisa, o conceito mais adequado é a concepção de Dallari (1998), que defende a soberania como um dos elementos do Estado, um de seus princípios estruturais.

Corroborando com os pressupostos de Dallari, Reale (2000 apud NETO, 2011) acrescenta:

Revista Eletrônica da ANPHLAC, ISSN 1679-1061, n. 16, p. 115 -134, Jan./Jul. 2014. http://revista.anphlac.org.br 


\begin{abstract}
A Soberania é tanto a força ou o sistema de forças que dá nascimento ao Estado Moderno e preside o seu desenvolvimento, quanto à expressão jurídica dessa força no Estado constituído segundo os imperativos éticos, econômicos, religiosos etc., da comunidade nacional, mas não é nenhum desses elementos separadamente: a soberania é sempre sócio - político - jurídica, ou não é soberania. É esta necessidade que nos permite considerar concomitantemente os elementos da soberania que nos permite distingui-la como uma forma de poder peculiar ao Estado Moderno.
\end{abstract}

A soberania, assim, é um atributo de ordem jurídica, do sistema de autoridade do governo e do povo. A soberania é, e será sempre, sócio/jurídica/política, não podendo ser somente uma destas, ou então não é soberania.

Assim percebe-se uma relativização do conceito de soberania ao decorrer dos tempos, pois na concepção atual

A soberania é uma concepção política que não pode ser limitada por nenhum outro poder. É una, integral e universal, não podendo sofrer restrições de qualquer tipo, salvo as decorrentes dos imperativos de convivência pacífica entre as nações soberanas (MALUF, 1999 apud NETO, 2011).

Trata-se, aqui, não do desaparecimento da soberania nacional ou o surgimento de um Leviatã supranacional com a assinatura de tratados, como foi o Tratado de Cooperação Amazônica (TCA). Mas sim, nações diferentes, com suas soberanias nacionais preservadas, vivenciando fins/objetivos comuns, que neste, é o fortalecimento de suas soberanias contra o discurso da internacionalização da Amazônia tão em voga na década de 1970.

\title{
Integração em defesa e fortalecimento da soberania nacional dos países partícipes do Tratado de Cooperação Amazônica
}

Um dos pontos centrais na análise do Tratado de Cooperação Amazônica é a questão da soberania, principalmente no que tange ao alcance e aos limites desta, pois como defende Bodin, a soberania é o eixo pelo qual o Estado se move e um de seus elementos, um de seus princípios estruturais (DALLARI, 1998).

Revista Eletrônica da ANPHLAC, ISSN 1679-1061, n. 16, p. 115 -134, Jan./Jul. 2014. http://revista.anphlac.org.br 
Os países desenvolvidos sustentavam a ideia de que a exploração dos recursos naturais de um país tinha consequências sobre os demais. Dessa forma, a soberania nacional não poderia impedir certo controle internacional. Daí decorre o ideal de internacionalização de determinadas regiões, como por exemplo, a região amazônica (ANTIQUERA, 2006; MOREIRA, 2012).

Este ponto é bastante sensível para os países menos desenvolvidos, pois estes defendem o pleno uso de seus recursos naturais, inclusive para o desenvolvimento de seus países. Estes enxergavam a internacionalização como uma forma de enfraquecimento e limitação de sua soberania nacional (ANTIQUERA, 2006; MOREIRA, 2012). Mas nos pressupostos de Kelsen, o conceito de soberania não é jurídico, e não pode ser analisada por esses termos, por isso, não pode ser pensado somente em caráter interno, mas externamente, pois este não visualiza fronteiras entre o ordenamento jurídico nacional e o internacional. E indo mais além, Heller defende que o direito internacional estaria fortalecido através do fortalecimento dos Estados soberanos, pois estes são as unidades fundamentais e constituintes deste (HELLER, 1995; HERMANN, 2011; ROCHA, 2009).

Percebe-se então, a grande ênfase dada à questão da preservação do meio ambiente. Nesse aspecto, a Conferência de Estocolmo em 1962 tem papel fundamental. Importante ressaltar que essa grande preocupação em relação à preservação do meio ambiente coloca em xeque a plena autonomia de uma nação no que tange a formulação de sua política de utilização e preservação dos seus recursos naturais o que consequentemente limita sua utilização do espaço e coloca em declínio a noção de soberania, pois como visto anteriormente este é um dos conceitos basilares na concepção de estado (ANTIQUERA, 2006; DALLARI, 1998; MOREIRA, 2012).

Nesse aspecto, o Tratado de Cooperação Amazônica, fruto de uma época, de um contexto, demonstra que está ciente desse possível enfraquecimento da soberania nacional dos países amazônicos. Segundo Antiquera (2006), no texto original do tratado, há a menção de uma possibilidade de integração para a defesa da região, ideia que cai já na segunda rodada de negociações, pois se pensava que essa questão poderia gerar especulação de uma possível integração supranacional na região, integração militar inclusive, por essa razão, o TCA destaca que:

Revista Eletrônica da ANPHLAC, ISSN 1679-1061, n. 16, p. 115 -134, Jan./Jul. 2014. http://revista.anphlac.org.br 


\section{ARTIGO XVI}

As decisões e compromissos adotados pelas Partes Contratantes na aplicação do presente Tratado não prejudicarão os projetos e empreendimento que executem em seus respectivos territórios, dentro do respeito ao Diretor Internacional e segundo a boa prática entre nações vizinhas e amigas (TCA, 1978).

Diante de tal contexto, o Tratado de Cooperação Amazônica é bastante enfático, pois as nações

Cônscias de que tanto o desenvolvimento socioeconômico como a preservação do meio ambiente são responsabilidades inerentes à soberania de cada Estado e que a cooperação entre as Partes Contratantes servirá para facilitar o cumprimento destas responsabilidades, continuando e ampliando os esforços conjuntos que vêm realizando em matéria de conservação ecológica da Amazônia (TCA, 1978).

\section{ARTIGO IV}

As Partes Contratantes proclamam que o uso e aproveitamento exclusivo dos recursos naturais em seus respectivos territórios é direito inerente à soberania do Estado e seu exercício não terá outras restrições senão as que resultem do Direito Internacional.

Ou seja, a conservação, preservação e exploração são de exclusiva responsabilidade dos países pertencentes à região amazônica. Não cabendo a nenhum outro país a interferência no que tange essa questão, pois como se viu, o discurso da internacionalização estava bastante em pauta na década de 1970, ou seja, a internacionalização com justificativas ecológicas (ANTIQUERA, 2006; MOREIRA, 2012).

Os historiadores dos conceitos procuram fazer da reconstrução contextual um meio para a compreensão de transformações mais amplas do processo histórico (KOSELLEK, 2006). No caso, no presente trabalho, a compreensão dos conceitos geopolíticos que permeiam a década de 1970, como os de integração e soberania.

O projeto da História dos Conceitos procura articular análises sincrônicas e diacrônicas: o exame comparativo e sincrônico do emprego de certos conceitos em determinado momento histórico e a chave interpretativa para a análise diacrônica da dinâmica do processo histórico estudado, principalmente no que tange as suas transformações estruturais e profundas. Ou seja: a História dos conceitos procura 
analisar as grandes mudanças da História por meio do estudo cuidadoso das transformações de certos conceitos (KOSELLEK, 2006). Como o de soberania e de integração, por exemplo.

O estudo destes conceitos, presentes no TCA, possibilita-nos evidenciar através da análise deste, que a conservação do Estado e da soberania nacional, depende da integração dos países da pan-amazônia. Pois como explicita Ginesta (1999), essa integração permite uma nova e dinâmica unidade política com maiores recursos e capacidade de resolução de problemas comuns. No trabalho aqui apresentado, a problemática é a internacionalização da Amazônia e o enfraquecimento das soberanias nacionais dos países ali localizados. E como solução viável, uma integração possibilitaria uma defesa diante da problemática apresentada. Ou seja, a integração fortaleceria a soberania de cada país e como consequência a preservação tanto da soberania quanto do próprio estado nacional destes.

\section{Considerações Finais}

O presente trabalho não tem por pretensão esgotar a reflexão e estudo do conceito de soberania na região amazônica. As décadas após a Segunda Guerra Mundial explicitam uma época de crises profundas e rupturas importantes, destas pode-se citar a crise econômica, a Deténte da década de 1960, para o fim da paz, por uma instabilidade internacional na década subsequente, a nova postura brasileira no governo Geisel, com o chamado "pragmatismo responsável" em relação à política externa. Todos esses fatores influenciaram na elaboração e assinatura do Tratado de Cooperação Amazônica em 1978.

Dentre os principais objetivos na assinatura do Tratado de Cooperação Amazônica, pode-se citar: a promoção do desenvolvimento da região amazônica que no caso dependeria de uma integração dos países partícipes, em defesa e fortalecimento da soberania nacional destes, contra uma possível internacionalização da região.

O Brasil tinha interesses próprios na assinatura do TCA, como uma melhoria na relação entre este e os países latino-americanos. Sabe-se que desde meados de 1976, o Itamaraty tinha ideias de acordos multilaterais com os países amazônicos. E que se buscava uma cooperação entre estes a fim de promover um desenvolvimento harmônico

Revista Eletrônica da ANPHLAC, ISSN 1679-1061, n. 16, p. 115 -134, Jan./Jul. 2014. http://revista.anphlac.org.br 
da região. No governo de Ernesto Geisel, este objetivo ganhou força com o “pragmatismo responsável”, em que o TCA é fruto.

Mas além de estreitar laços e romper com a desconfiança dos países latinoamericanos, o Brasil ansiava por uma inserção e não exclusão do país perante a América Latina, principalmente na parte norte, materializada após a assinatura do Pacto Andino em 1969. Dessa forma, pode-se afirmar que o Tratado de Cooperação Amazônica, cumpre um papel importante em relação a essa temática, pois é um meio para a possibilidade deste objetivo.

Os países partícipes da assinatura do Tratado de Cooperação Amazônica estavam a par que o desenvolvimento da região, estava ligada à busca de uma integração regional, somente a partir de tal, a região poderia desenvolver-se de forma harmônica e a fim da resolução de problemáticas comuns, tendo em vista que estes compartilham o espaço amazônico, com suas particularidades, mas que apresentam aspectos comuns, tais como a colonização e sociedades plurais. E na década de 1970, as problemáticas apresentadas são bastante complexas, tais como a retórica de uma possível internacionalização da região, o que entraria em choque com a soberania de cada nação pertencente à Amazônia.

Importante ressaltar que esta integração, era necessária para o desenvolvimento da região, levando em conta sua grande riqueza natural, e em defesa e no fortalecimento da soberania nacional dos países amazônicos. Um dos pontos centrais na análise do Tratado de Cooperação Amazônica é a questão da soberania, principalmente no que tange ao alcance e aos limites desta.

Dessa forma, pode-se afirmar que o TCA, possibilita que nações diferentes, com suas soberanias nacionais preservadas, vivenciem fins/objetivos comuns, que neste, é o fortalecimento de suas soberanias contra o discurso da internacionalização da Amazônia tão em voga na década de 1970 e consequentemente do próprio Estado nacional.

A grande importância do Tratado de Cooperação Amazônica e justificada, pois através de seu estudo, pode-se vislumbrar os conceitos gestados na década de 1970 e que ao analisarmos tais, compreendemos o referido período. Este também é o inicio de

Revista Eletrônica da ANPHLAC, ISSN 1679-1061, n. 16, p. 115 -134, Jan./Jul. 2014. http://revista.anphlac.org.br 
uma possibilidade de integração regional entre os países amazônicos, o que justifica também seu estudo.

Por fim, o Tratado de Cooperação Amazônica não é um fim em si mesmo, mas acena para muitas possibilidades de leitura e interpretação, principalmente para uma compreensão da realidade histórica da região amazônica. Como vemos o campo da História das Relações Internacionais e o TCA para o estudo da década de 1970 na região se mostra profícuo e com múltiplas possibilidades.

\section{Referências Bibliograficas:}

ALVES, Maria Helena Moreira. Estado e Oposição no Brasil (1964-1984). Bauru/SP: Edusc, 2005.

ANTIQUERA, Daniel de Campos. A Amazônia e a política externa brasileira: análise do Tratado de Cooperação Amazônica (TCA) e sua transformação em organização internacional (1978-2002). Campinas, 2006. Dissertação (mestrado). Universidade Estadual de Campinas, Centro de Filosofia e Ciências Humanas.

ARQUIDIOCESE DE SÃO PAULO. Brasil: nunca mais. 30ªed. Petrópolis/RJ: Vozes, 1999.

BARROS, José D'Assunção. O campo da história: especialidades e abordagens. $5^{\mathrm{a}}$ ed. Petrópolis/RJ: Vozes, 2008.

BOBBIO, Norberto; MATTEUCCI, Nicola; PASQUINO, Gianfranco. Soberania. In: Dicionário de política. Brasília: Editora Universidade de Brasília, 1998, p. 1179-1198.

CALDERON, Andrés Fernando Piedra. A Organização do Tratado de Cooperação Amazônica e a Consolidação do Processo de Integração Sul-Americana. Porto Alegre: 2007.

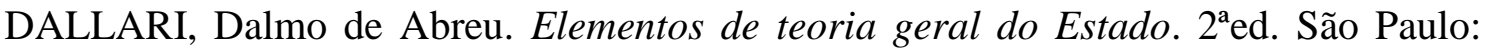
Editora Saraiva, 1998.

DIAS, Monica Nazaré Picanço; SOUZA, Danielle Costa de. A soberania nacional na Amazônia legal sob a ótica da doutrina internacionalista

pátria.Disponível:<www.conamp.org.br/Lists/.Nicolás\%20Rodriguez\%20Garcia\%20.p

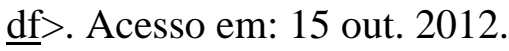

Discurso de Ernesto Geisel, 19 de março de 1974. Disponível em: <www.biblioteca.presidencia.gov.br>. Acesso em: 18 fev. 2013.

Discurso de posse de Azeredo da Silveira, 1974. Disponível em: <www.ri.fgv.br/node/499>. Acesso em: 18 fev. 2013.

DUROSELLE, Jean-Baptiste. Todo o império perecerá. Trad. Ane Lize Spaltemberg de S. Magalhães. Brasília: Editora Universidade de Brasília: São Paulo: Imprensa Oficial do Estado, 2000.

Revista Eletrônica da ANPHLAC, ISSN 1679-1061, n. 16, p. 115 -134, Jan./Jul. 2014. http://revista.anphlac.org.br 
GINESTA, Jacques. El Mercosur y su Contexto Regional e Internacional. Porto Alegre: Ed. Universidade - UFRGS, 1999.

GUERRA, Sidney. Soberania (Antigos e novos paradigmas). Rio de Janeiro: Freitas Bastos Editora, 2004.

HELLER, Hermann. La soberania: contribuición a la teoria del derecho estatal del derecho internacional. Santiago de Chile: Unam y FCE, 1995.

HERMANN, Breno. Soberania, não intervenção e não indiferença: reflexões sobre o discurso diplomático brasileiro. Brasília: Fundações Alexandre de Gusmão, 2011.

HOBBES, Thomas. Leviatã: ou matéria, forma e poder de um Estado eclesiástico e civil. Trad. Alex Marins.- São Paulo: Editora Martin Claret, 2007.

HOBBSBAWM, Eric J. Era dos Extremos: o breve século XX 1914-1991. - Trad. Marcos Santarrita; revisão técnica: Maria Célia Paoli. - São Paulo: Companhia das Letras, 1995.

KOSELLEK, Reinhart. Passado Futuro: contribuição à semântica dos tempos históricos. - Trad. Wilma Patrícia Maas, Carlos Almeida Pereira; revisão da tradução César Benjamin. Rio de Janeiro: Contraponto, 2006.

KOSELLEK, Reinhart. Uma história dos conceitos: problemas teóricos e práticos. Estudos Históricos: Rio de Janeiro, vol. 5, n. 10, 1992, p. 134-146.

KUPCHAN, Charles A. The Persian Gulf and the West: The Dilemmas of Security. Boston: Allen \& Unwin, 1987.

LEITE, Patrícia Soares. O Brasil e a cooperação Sul-Sul em três momentos: os governos Jânio Quadros/João Goulart, Ernesto Geisel e Luiz Inácio Lula da Silva. Brasília: Fundação Alexandre de Gusmão, 2011.

LIGIERO, Luiz Fernando. A autonomia na política externa brasileira: a política externa independente e o pragmatismo responsável: momentos diferentes, políticas semelhantes?. Brasília: Fundação Alexandre de Gusmão, 2011.

LYRA JUNIOR, A. A. "Fronteiras internas" da América do Sul: reflexões preliminares sobre o Estado peruano na configuração do imediato Pós-Guerra Fria. Boa Vista: 2013. No prelo.

LOHBAUER, Christian. Brasil - Alemanha: fases de uma parceria (1964-1999). São Paulo: Fundação Adenauer, 2000.

MARINHO. Henrique Jorge Medeiros. O estudo das Relações Internacionais: teorias e realidade. São Paulo: Aduaneiras, 2008.

Revista Eletrônica da ANPHLAC, ISSN 1679-1061, n. 16, p. 115 -134, Jan./Jul. 2014. http://revista.anphlac.org.br 
MORE, Rodrigo F. $O$ moderno conceito de soberania no âmbito do direito internacional. Disponível em: 〈www.more.com.br/artigos/Soberania.pdf > . Acesso em: 15 out. 2012.

MOREIRA, Paula Gomes. Política externa brasileira para a Amazônia: imperativos, atores e políticas (1964-2002). Dissertação (Mestrado em Relações Internacionais) Instituto de Filosofia e Ciências Humanas, Universidade do Estado do Rio de Janeiro: Rio de Janeiro, 2012.

MORGENTHAU. Hans J. A política entre as nações: a luta pelo poder e pela paz. Brasília: Editora Universidade de Brasília, 2003.

NETO, Francisco Jose Vilas Boas. A relativização do conceito de soberania.

Disponível em: $<$ www.jandrade.edu.br/fonte_universitaria/artigos/artigo_06.pdf $>$.

Acesso em: 15 out. 2012.

RIBEIRO, Renato Janine. Hobbes: o medo e a esperança. In: Os clássicos da política. WEFFORT, Francisco C. (org). 14 ed. São Paulo: Atica, 2006, p. 51-77.

ROCHA, Luiz Alberto G. S. Soberania e Internacionalização da Amazônia. Disponível <www.oab.org.br/editora/revista/1235067057174218181901.pdf > . Acesso em: 15 out. 2012.

ROSSONI, Sandra dos Reis M.; TRINTIN, Jaime Graciano. Os Anos Dourados do capitalismo: breve abordagem sobre o crescimento capitalista.Disponível:http://revistas.unipar.br/akropolis/article/view/1759/1528.pdf. Acesso em: 25 dez.2012.

SANTOS, Nélvio Paulo Dutra. Políticas públicas, economia e poder. O Estado de Roraima entre 1970 e 2000. Belém, 2004. 270f. Tese (Doutorado em História). Núcleo de Altos Estudos da Amazônia, Universidade Federal do Pará.

SILVA, Angela Maria Moreira. Normas para apresentação dos Trabalhos TécnicoCientíficos da UFRR: baseadas nas normas da ABNT. Boa Vista/RR: EdUFRR, 2011.

SILVA. Francisco Carlos Teixeira. Crise da Ditadura Militar e o Processo de Abertura Política no Brasil, 1974-1985. In: O Brasil Republicano: O Tempo da Ditadura.

DELGADO, Lucília de Almeida Neves; FERREIRA, Jorge (Org). - 2ªed.- Rio de Janeiro: Civilização Brasileira, 2007.

SILVA, Kalina Vanderlei; SILVA, Maciel Henrique. Dicionários de Conceitos Históricos. São Paulo: Contexto, 2005.

Tratado de Cooperação Amazônica, 1978.

Revista Eletrônica da ANPHLAC, ISSN 1679-1061, n. 16, p. 115 -134, Jan./Jul. 2014. http://revista.anphlac.org.br 
VIZENTINI, Paulo G. Fagundes. Détente, Revoluções e Crise Econômica/1964-1979 e A Reação Conservadora dos Anos 80. In: Da Guerra Fria à Crise (1945-1989): as relações internacionais do século 20. $4^{a}$ ed. Porto Alegre: Editora UFRGS, 2006.

Revista Eletrônica da ANPHLAC, ISSN 1679-1061, n. 16, p. 115 -134, Jan./Jul. 2014. http://revista.anphlac.org.br 